Ciência e Natura, Santa Maria, v. 37 n.42 jun. 2015, p. 251-261

Revista do Centro de Ciências Naturais e Exatas - UFSM

ISSN impressa: 0100-8307 ISSN on-line: 2179-460X

\title{
ciênciaenatura
}

\section{Diagnóstico da disposição dos resíduos sólidos da construção civil na cidade de Montes Claros, MG}

Provision of the diagnosis of solid waste construction in the city of Montes Claros, MG

\author{
Sheila Abreu Mourão1, Victor Rodrigues Aragão², Daise Anne Pereira Meira Damasceno \\ ${ }^{1}$ Universidade Federal de Viçosa - UFV, Viçosa, MG, Brasil. \\ 2 Universidade Federal de Santa Maria, Frederico Westphalen, RS - Brasil \\ ${ }^{3}$ Faculdades Integradas Pitágoras, Brasil.
}

\begin{abstract}
Resumo
A expansão do setor da construção civil na cidade de Montes Claros (MG) vem acarretando um significativo aumento na geração de resíduos sólidos, que frequentemente são depositados em locais irregulares. Mas, ações têm sido adotadas para reverter estes impactos ambientais, entre elas a promulgação de leis municipais que estabelecem diretrizes, critérios, procedimentos para a gestão dos resíduos da construção e demolição $(R C D)$ e determinam responsabilidades entre os geradores, transportadores e os órgãos municipais. O presente estudo objetivou estimar a geração e mapear os principais locais de disposição irregular dos RCD de Montes Claros. Para tanto, a pesquisa foi realizada em duas etapas, primeiramente visitou-se os órgãos públicos estaduais e municipais e agentes envolvidos na geração e coleta de entulhos em Montes Claros, e desta forma buscou-se informações necessárias para estimar a geração dos RCD. Já, o mapeamento dos locais de deposição do RCD se deu por meio de levantamentos fotográficos in loco em pólos regionais determinados pela Prefeitura Municipal da cidade. Com a pesquisa foi possível compreender os agentes envolvidos na geração, tratamento e disposição dos resíduos sólidos relacionados à construção civil na cidade de Montes Claros. Em que foi constatada disposições irregulares em dessemelhantes pontos da cidade. Fato que promove a degradação dos diversos ambientes envolvidos direta e indiretamente a esses materiais; e que a implantação de programas de gerenciamento de resíduos relacionas à construção civil é o fator norteador para a redução do volume desses materiais no município.
\end{abstract}

Palavras-chave: Geração, Coleta, Entulhos, Degradação, Ambientes.

\begin{abstract}
The expansion of the construction sector in the city of Montes Claros (MG) has been causing a significant increase in the generation of solid waste, which are often deposited in irregular locations. But actions have been taken to reverse these environmental impacts, including the enactment of local laws that establish guidelines, criteria, procedures for the management of waste from construction and demolition and determine responsibilities between the generators, carriers and municipal agencies. This study aimed to estimate the generation and map the main irregular disposal sites of waste from construction and demolition in Montes Claros. Therefore, the survey was conducted in two stages, first visited to state and local public agencies and agents involved in generating and collecting debris in Montes Claros, and thus sought to information needed to estimate the generation of the waste from construction and demolition. Already, the mapping of the waste from construction and demolition disposal sites was through on-site photographic surveys in regional centers determined by the Municipality of the city. Through research it was possible to understand the agent involved in the generation, treatment and disposal of solid waste related to construction in the city of Montes Claros. That it was detected irregular provisions in dissimilar parts of the city. Apparel promoting the degradation of the various environments involved directly and indirectly to these materials; and that the deployment of relation to waste management programs for construction is the guiding factor for the reduction in the volume of these materials in the city.

Keywords: Generation, Collecting, Debris, Degradation, Environments.
\end{abstract}




\section{Introdução}

A situação dos resíduos da construção civil e demolição (RCD) é um grande problema para a humanidade levando em consideração os aspectos social, ambiental e econômico, especialmente em países subdesenvolvidos.

$O$ fato é que as atividades ligadas à construção civil em Montes Claros (MG) são responsáveis por uma quantidade considerável de resíduos, que são depositados inadequadamente em encostas de vertentes, ruas e lotes vagos, formando locais de deposições irregulares na cidade. Esses resíduos afetam a paisagem urbana, invadem pistas, atrapalham o tráfego, dificultam o escoamento de água pluvial, ocasionam poluição e degradação de áreas urbanas, além disso, são locais propícios à reprodução e abrigo de vetores de doenças, afetando a qualidade de vida da população.

$\mathrm{O}$ avanço e crescimento das cidades tendem a contribuir para o desenvolvimento da geração de RCD e o que se nota é que quanto mais construímos, destruímos e reformamos; mais resíduos produzimos.

Karpinski et al. (2008, p. 70) estima que "a construção civil consome algo entre 20 e $50 \%$ do total de recursos naturais consumidos pela sociedade." Para o autor, a geração de grandes volumes de resíduos de construção são provenientes dos canteiros de obras brasileiros, além dos materiais de demolição, que são responsáveis por cerca de 20 a 30\% do total dos resíduos gerados.

A deposição desses resíduos oferece grandes riscos à população, devido à destinação quase sempre ilegal, provocando contaminações e colocando em risco a saúde pública. Além da ocupação de solo e contaminação, a deposição desses resíduos representa também “[...] um grande desperdício de matérias-primas, as quais uma vez otimizados os processos, podem gerar sua reutilização, cortando custos e, portanto, gerando mais-valia primária" (TEIXEIRA, 2010, p. 15).

Nos últimos anos, o interesse por políticas públicas para os resíduos gerados pelo setor da construção civil tem se acirrado com a discussão de questões ambientais. Desprezar materiais, seja na forma de resíduo ou de qualquer outra natureza, significa desprezar recursos naturais, o que põe a indústria da construção civil no centro das discussões na procura pelo desenvolvimento sustentável nas suas distintas extensões (SOUZA et al., 2004).

Diante dessa problemática, busca-se nesta proposta de pesquisa diagnosticar a situação de disposição dos RCD do município de Montes Claros (MG), com o intuito de obter informações úteis para a elaboração de um plano de gestão de resíduo de construção e demolição adequado às diretrizes das disposições legais com o meio ambiente.

\section{Metodologia}

\subsection{Caracterização do município}

A área de referência para o presente estudo é a cidade de Montes Claros, um município considerado de porte médio, localizado no norte de Minas de Gerais, como mostra a figura 1; com área da unidade territorial compreendida em $3.568,941 \mathrm{~km}^{2}$, de densidade demográfica de 101,41 hab. $/ \mathrm{km}^{2}$ e uma com população urbana estimada em 2013 de 385.898 habitantes (IBGE, 2013).

A cidade é o foco da análise por apresentar um grande desenvolvimento no setor de construção e demolição. Com o crescimento acelerado e o aumento de obras, nota-se a presença de focos de pontos clandestinos de depósitos de entulhos; ação que é realizada muitas vezes de forma incorreta na cidade, o que revela a falta de compromisso ou, em alguns casos, a inexistência de políticas públicas que disciplinam e ordenam os fluxos da destinação dos resíduos da construção civil na cidade, provocando grandes impactos ambientais e, consequentemente, risco à população.

Diante dessa situação, o presente estudo buscou conhecer e identificar através de pesquisa bibliográfica, contribuições técnicas e científicas a respeito dos RCD, bem como sua caracterização, problemas gerados, o impacto sob o meio, normas, leis e resoluções, nos quais delimitam o gerenciamento dos resíduos sólidos da construção e demolição.

O desenvolvimento do trabalho se constituiu pela busca de informações documentais realizadas no período de agosto de 2012 a fevereiro de 2015, que possibilitou a descrição dos aspectos básicos do município de Montes 


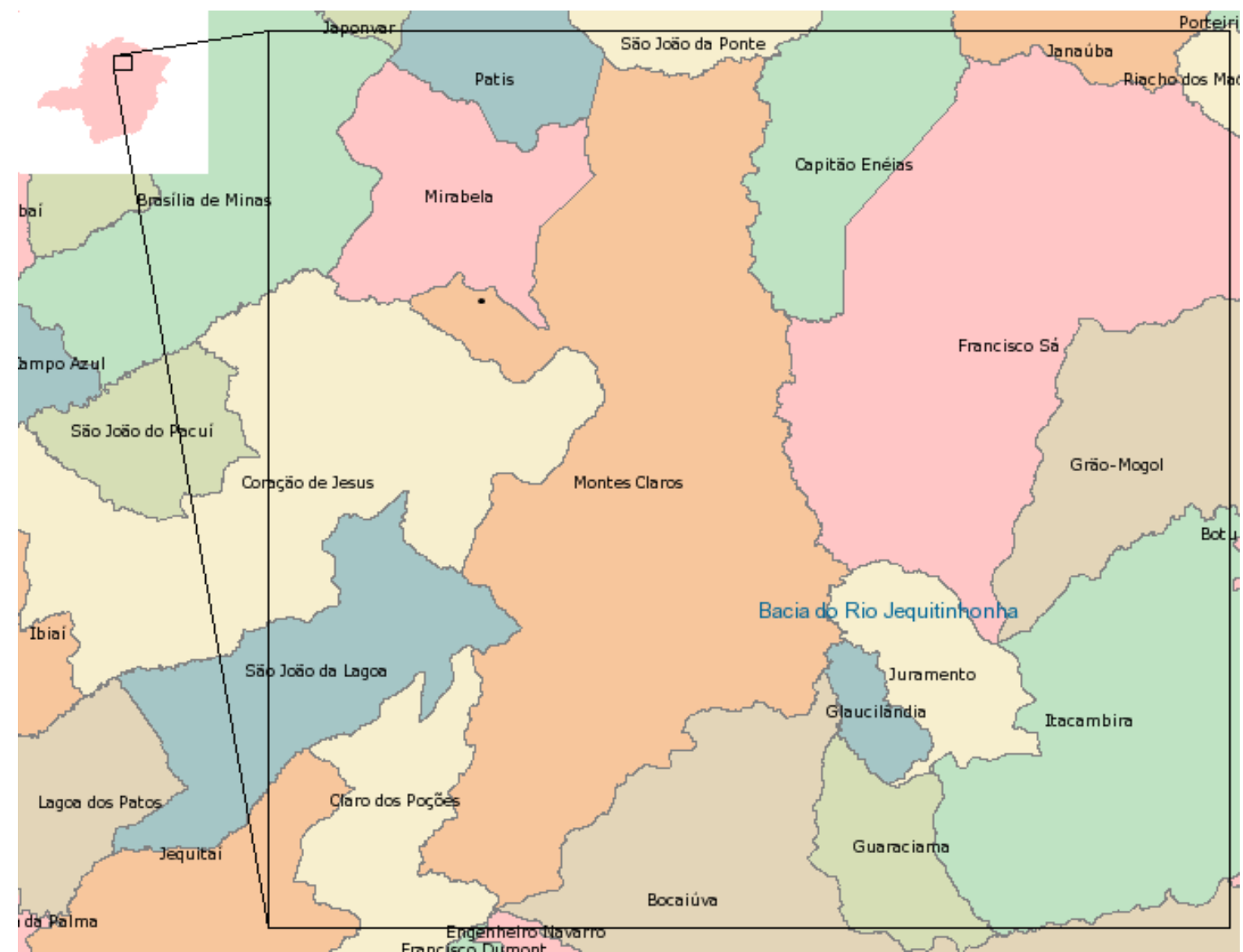

Figura 1: Representação da área estudada (IGA, 2015).

Claros para a identificação das principais formas de deposição e levantamento de dados para descrever as localização das áreas de disposição e a quantidade de RCD gerados.

Para descrever os locais de disposição e estimar a quantidade de resíduos sólidos da construção civil gerada em Montes Claros, foi feita uma coleta de dados por meio de uma pesquisa de campo, na área do objeto da pesquisa e um mapeamento dos pontos considerados mais críticos. A técnica de pesquisa adotada foi a entrevista não-estruturada, com auxílio de registro fotográfico, como forma de explorar mais amplamente a questão da deposição irregular e destinação dos RCD. Marconi (1999) afirma que não existe rigidez no roteiro da entrevista não-estruturada, na qual permite que se explore mais amplamente algumas questões.

Posteriormente, o procedimento da pesquisa quantitativa tratou-se de um questionário aplicado a (05) cinco empresas do setor da construção civil com intuito de identificar os agentes envolvidos na geração dos RCD.
Finalmente, fez-se uma análise contígua de todas as informações reunidas objetivando descrever a existência de problemas, bem como as consequências causadas pela disposição irregular dos resíduos sólidos além de demonstrar a importância de um plano de gerenciamento de resíduos sólidos para o município.

\section{Resultados e discussão}

\subsection{Levantamento da quantidade de RCD gerados em Montes Claros}

Montes Claros sofreu um crescimento acelerado e a construção civil mostra números que justificam a quantidade de RCD gerados no ambiente urbano: quanto mais reforma, mais novas edificações, mais RCD são gerados.

Um problema que surge com esse crescimento é que nem tudo que está sendo construído ou reformado, em Montes Claros, é legalmente registrado, tanto no Conselho 
Regional de Engenharia e Agronomia (CREAMG) como na Prefeitura Municipal de Montes Claros. Portanto, os números de RCD retirados de áreas irregulares podem ser tão altos quanto os de áreas regulares.

Segundo informações obtidas pela ESURB em fevereiro de 2013, dados indicam o número de aproximadamente 131.000 ton.ano $^{-1}$ e resíduos sólidos gerados no município de Montes Claros.

Para o mapeamento dos locais regulares de deposição dos RCD de Montes Claros, o município foi dividido em pólos regionais, dados fornecidos pela Prefeitura Municipal e retirados um total de 83.279,50 $\mathrm{m}^{3}$ no ano de 2012. Considerando os 12 polos identificados de acordo com dados fornecidos pela Empresa de Serviços Urbanos, temos os seguintes volumes cadastrados: (Santos Reis com 903,00), (Central com 1.029,00), (São Judas com 6.483,00), (Vila Oliveira com 5.421,20), (Delfino Magalhães com $9.736,00$ ), (JK com 3.456,00), (Maracanã com 8.521,80), (Independência com 3.624,20), (Morrinhos com 14.989,70), (Major Prates com 13.856,00), (Cintra com 2.498,60) e (Renascença com 12.761,00 de entulho/m3).

A partir desta divisão foi realizada uma pesquisa in loco de pontos visualmente considerados críticos, onde o entulho de construção civil é ou era frequentemente encontrado depositado em local considerado irregular. O que se chama de "local irregular" fica definido seguindo critérios abaixo:

- Deposição de Resíduos - Atividade intermediária, anterior à destinação final de resíduos sólidos, realizada de forma irregular e quase sempre ilegal.

- Disposição de Resíduos - Atividade intermediária ou final, com manejo e arranjo corretos dos resíduos envolvidos.

- Bota-foras - Áreas públicas ou privadas para disposição de resíduos predominantemente inertes, que absorvem, principalmente, os resíduos da construção e demolição.
Pôde verificar que diante da situação desordenada de deposição dos resíduos da construção e demolição, o poder público municipal atua, lentamente, com medidas paliativas, realizando serviços de coleta e arcando com os custos do transporte e da disposição final. Tal prática não soluciona definitivamente o problema por não conseguir a remoção total do RCD devido ao grande volume de entulho gerado diariamente. Ao contrário, incentiva a continuidade da disposição irregular nos locais atendidos pela limpeza pública da administração municipal.

É de competência do município, dirigir políticas públicas para o adequado manejo dos RCD na cidade, com o objetivo de providenciar o local de disposição final e fiscalizar a disposição em áreas não regulamentadas. $\mathrm{O}$ descarte acontece em terrenos baldios e ao longo dos mananciais, o que pode ocasionar problemas urbanos como enchentes, tráfego dificultado, aspectos negativos na paisagem urbana, foco de insetos, roedores, dentre outros já citados anteriormente diretamente ligados ao impacto ambiental e a qualidade de vida.

Marques Neto (2005) assegura que, para amortizar o acondicionamento irregular dos resíduos é necessário instalações de pontos de recebimento de RCD em diferentes locais, assim as empresas coletoras e os pequenos geradores descarregarem em locais apropriados, como por exemplo a implementação adequada do CASCO. Com isso pode-se garantir a sustentabilidade dos locais de disposição de RCD e diminuir os efeitos do descarte inadequado.

\subsection{Identificação dos locais} regulamentados e dos agentes envolvidos na geração e destinação dos resíduos da construção civil em Montes Claros

Foi verificado junto à Empresa de Serviços Urbanos (ESURB), da Prefeitura Municipal de Montes Claros (MG), os locais de disposição regular de RCD existentes no Município. A partir da identificação das áreas de disposição regular, iniciou-se a identificação das áreas incluídas na Figura 2. 
Foi possível identificar os agentes envolvidos no descarte. Os locais mapeados na Figura 2, foram considerados pontos críticos e definidos para a implantação de 9 pontos de recebimento de entulho. Esses foram transformados em Centro de Apoio aos Carroceiros (CASCO). O mesmo foi fundado em 2006 com o objetivo de combater o descarte irregular de entulho. Foi planejado para normalizar o descarte dos Resíduos Sólidos através de unidades receptoras localizadas próximas aos geradores, oferecendo lugar apropriado para descarga controlada de entulhos. representa um significativo envolvimento na redução dos resíduos sólidos dispostos de forma irregular na cidade.

De acordo com o projeto dos CASCOs, cada um desses pontos deveriam ser em terrenos disponibilizados pela prefeitura, contendo uma rampa escavada no terreno natural, apoiada em dormentes de madeira, onde o material é despejado dentro de caçambas estacionárias dispostas na parte inferior da rampa. No local também cercariam a área e disponibilizariam um funcionário para monitorar o recebimento dos entulhos trazidos pelos carroceiros cadastrados

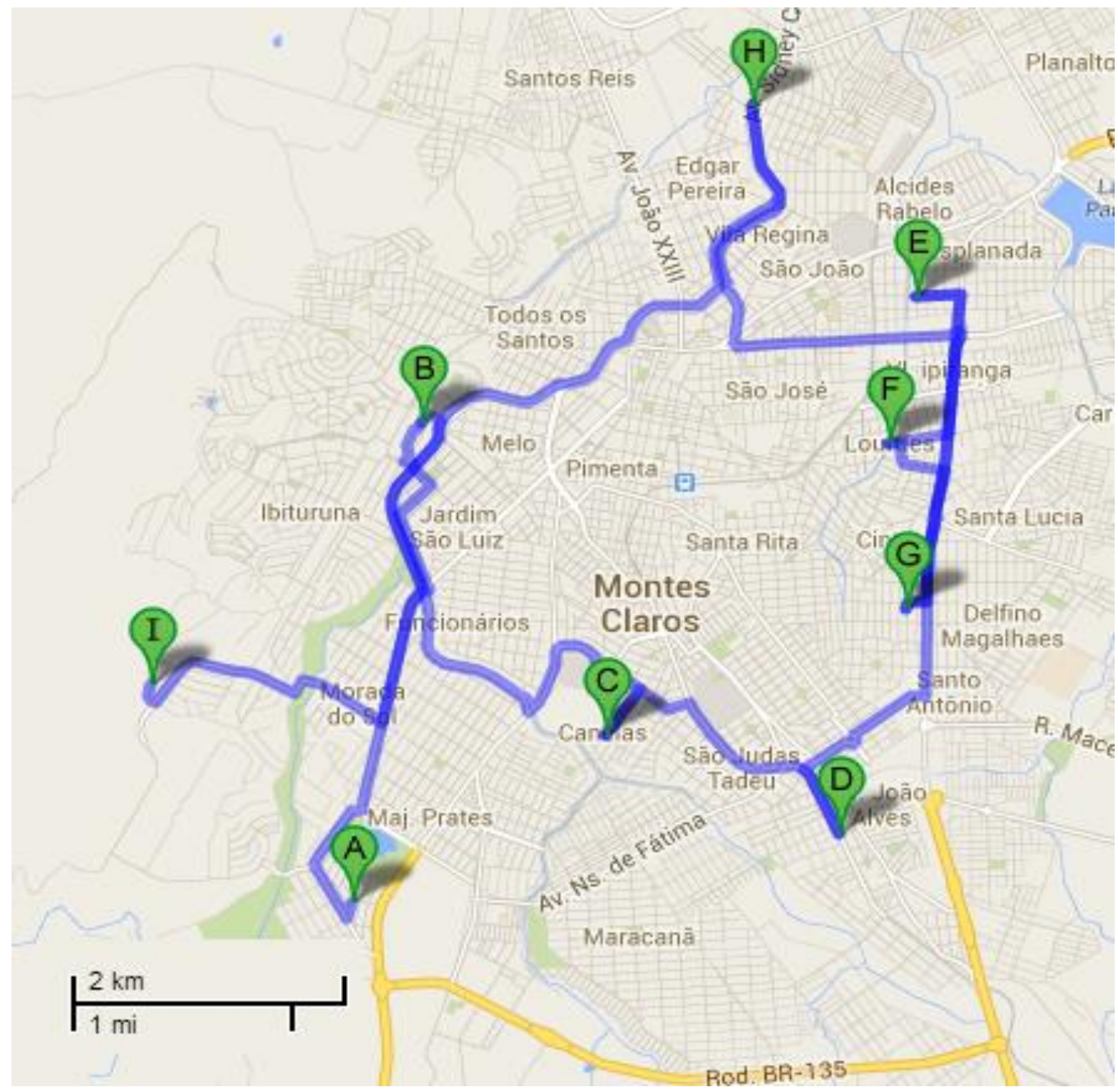

Figura 2: Localização dos pontos de apoio CASCOs implantados pela prefeitura de Montes Claros. (A) Bairro Ibituruna; (B) Morada do Parque; (C) Bairro Canelas; (D) Avenida São Judas; (E) Bairro Vera Cruz; (F) Bairro de Lourdes; (G) Bairro Nossa Senhora de Fátima; (H) Bairro Alice Maia e (H) Subida para o Parque Sapucaia (Adaptado de Google Maps, 2013).

Somente nestes locais os mais de 1.800 carroceiros cadastrados são responsáveis, segundo estimativas, por recolher $70 \%$ dos entulhos gerados no município, fato que que atuam no município e que se cadastraram na ESURB recebendo no processo o emplacamento das carroças e a identificação de seus animais. A Figura 3 mostra a atual situação de pelo menos quatro dos noves CASCOs. 
Neste contexto, buscou-se conhecer os principais geradores de Resíduos Sólidos da Construção e Demolição aplicando entrevistas para 5 (cinco) construtoras com a intenção de verificar como o problema do RCD é entendido por esses geradores.

Em relação ao sistema construtivo, quatro entrevistados responderam que o sistema utilizado pela empresa é a estrutura convencional de concreto e vedações $(80 \%)$, e um respondeu que é a alvenaria estrutural $(20 \%)$, sendo que não houve respostas quanto à estrutura de aço e vedações.

A maior parte dos entrevistados reconhece como serviços que mais geram resíduos a vedação vertical e o revestimento de paredes; como mostra a Figura 4.
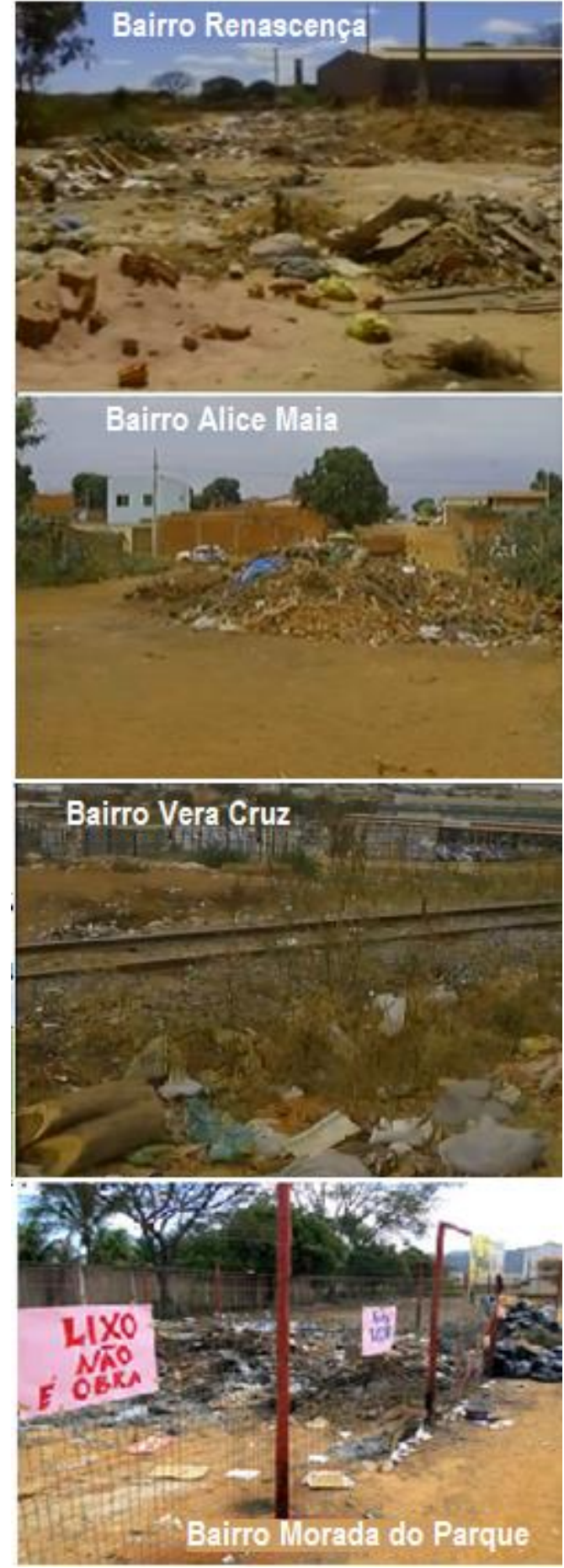

Figura 3: Deposição irregular de resíduos sólidos em alguns pontos considerados regulares pela secretaria de serviços urbanos de Montes Claros- MG, em 2013, CASCOs. (A) Bairro Renascença; (B) Bairro Vera Cruz; (C) Bairro Alice Maia e (C) Bairro Morada do Parque (Próprios autores). 


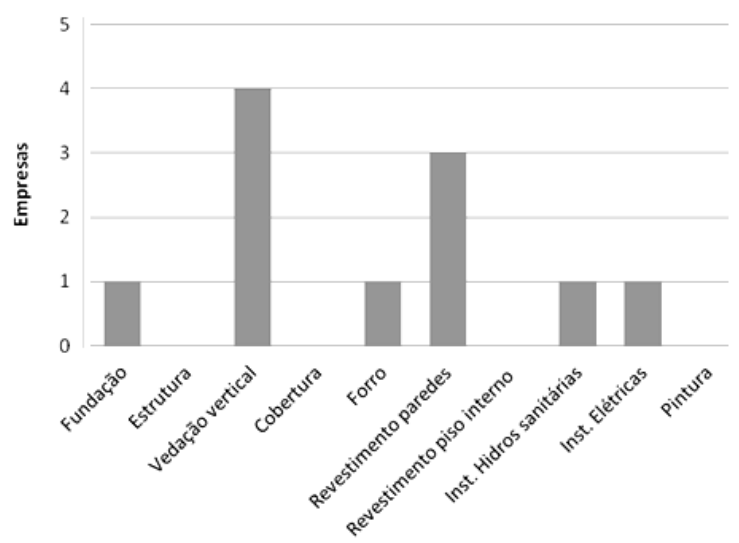

Figura 4: Serviços que mais geram RCD (Próprios autores).

Os resíduos mais problemáticos, considerando aspectos de volume mais listados pelos entrevistados, foram os tijolos e cerâmicas, sendo o primeiro, justificado por gerar alto volume de resíduos e serem caros. Foram também citados outros, como: cimento e barras de aço, cujo problema é o local onde são depositados, porque catadores começam a frequentar os locais para a retirada do ferro, com a intenção de comercializá-lo.

As principais causas da geração de resíduo mais citadas pelos entrevistados foram: Interferência pelo cliente, baixa capacitação de mão de obra e manejo dos materiais. Foi citada, com menos relevância, a baixa qualidade de projetos.

As principais formas de remoção de resíduos de obras indicam a precariedade do controle dos empreendedores, ou talvez a indiferença quanto a sua responsabilidade.

Em relação às principais formas de remoção dos RCD, percebe-se que os serviços de terceiros prevalece. A utilização por veículo próprio e por sucateiros foi mencionada. Nenhum entrevistado tem como principal forma de remoção de resíduo os carroceiros cadastrados no CASCO.

Um fato interessante em relação ao aterro disponível em Montes Claros para resíduos de obras é que a maiorias das empresas (60\%) não conhece. Apenas duas (40\%) conhecem o antigo lixão como local de destinação final para o RCD e apenas três o utiliza.

Pela resposta dos entrevistados, quatro empresas não vendem os resíduos coletados na obra (80\%). Apenas uma empresa vende madeira (20\%). Quatro das empresas não possuem sistema de resíduos implantados (80\%). Apenas uma possui sistema de resíduos implantados $(20 \%)$.

Houve uma diversificação nas respostas sobre quais os controles são adotados na obra em relação aos resíduos. Um entrevistado respondeu que controla os custos com captação e destinação; outro, com quantidade de resíduo gerado; um terceiro afirmou usar o controle feito por local de destinação, um afirmou não haver controle e um entrevistado não respondeu.

Em relação às Resoluções e Normas Técnicas, tem-se a seguinte análise: um entrevistado conhece todas as Resoluções; um conhece a Resolução CONAMA; outro, a NBR 1516, e dois entrevistados não conhece nenhum dos itens listados.

Analisados os dados acima, podemos concluir que a cidade Montes Claros tem como fonte de geração de resíduos de construção e demolição obras de novas edificações, reformas, ampliações e demolições. Pôde-se perceber que é necessário um trabalho de conscientização junto aos agentes envolvidos a fim de demonstrar a problemática da geração de RCD buscando soluções para a minimização destes resíduos e a importância do conhecimento das Resoluções e Leis vigentes. 
3.3. As principais formas de deposição dos resíduos sólidos da construção civil em Montes Claros

Foram identificados inúmeros pontos críticos de deposição irregular de RCD em Montes Claros, nos quais vem crescendo gradativamente pelo fato de não haver uma medida que evite
Fogliatti, Filippo e Goudard (2004) definem impacto ambiental como a alteração das propriedades físicas, químicas e/ou biológicas do meio ambiente, provocadas pela atividade humana. Essas afetam a saúde e a qualidade dos recursos naturais. Quando os impactos são negativos, podem levar à degradação ambiental.

Independente das características técnicas

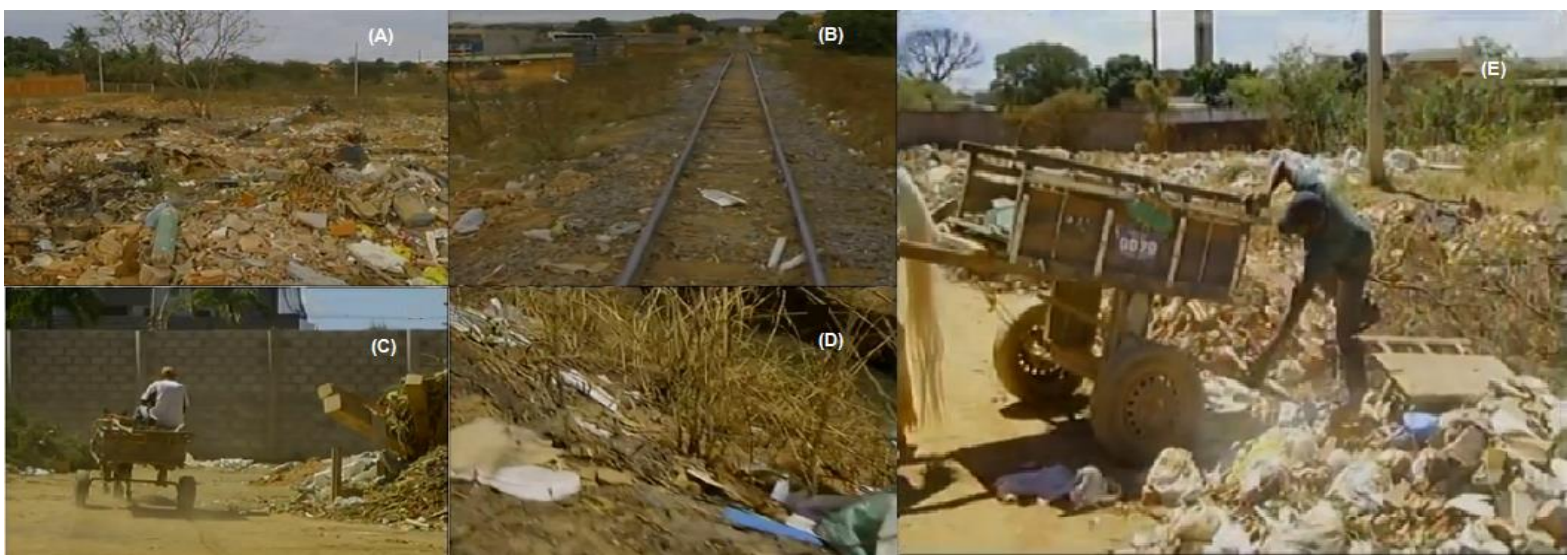

Figura 5: Principais formas de deposição dos resíduos sólidos em Montes Claros - MG. (A) Lote vago no bairro Renascença; (B) Adjacências da linha férrea no Bairro Roxo Verde; (C) Bairro Cristo Rei; (D) Encosta nas margens de um córrego no Bairro Todos os Santos e (E) Terreno de propriedade pública sendo utilizado para descarte de entulhos (Próprios autores).

este tipo de deposição.

Verificou-se que as principais formas de deposição dos resíduos sólidos da construção civil são em áreas de bota-foras e de deposição irregular, tais como: lotes vagos, encosta de córregos e linha férrea. Pôde-se notar que essas áreas estão localizadas na maioria, em bairros periféricos onde há um número maior de vazios urbanos e ainda por falta de espaços apropriados outros pontos da cidade estão sendo usados para o descarte de RCD.

A Figura 5 mostra alguns dos pontos críticos de deposição irregular de resíduos sólidos da construção civil verificados em março de 2013 em Montes Claros.

3.4. As principais formas de deposição dos resíduos sólidos da construção civil em Montes Claros entre áreas periféricas e centrais, as duas causam os seguintes impactos ambientais, que também foram observados na cidade de Montes Claros:

- Proliferação de vetores transmissores de doenças: Os locais de deposição irregulares de entulhos provocam atração de outros tipos de resíduos e dessa forma, tornam-se ambiente de proliferação de vetores transmissores de doenças;

- Degradação Ambiental: As deposições irregulares desses resíduos causam assoreamento dos cursos d'água, degradação de áreas de mananciais, obstrução em canais de águas pluviais que podem levar a inúmeros problemas como: enchentes e inundações;

- Obstrução de vias: O acúmulo dos resíduos em zonas de tráfego causa obstrução de vias de pedestres e de veículos.

Tais impactos e seus principais agravantes podem ser verificados também na Figura 2, citada acima. Ainda, outros problemas 
associados com a disposição de RCD puderam ser vistos na cidade, tais como: poluição visual; presença de odores desagradáveis; presença de catadores precariamente organizados, inclusive crianças; riscos de incêndio e desvalorização imobiliária no entorno.

Segundo a Lei do Município de Montes Claros nº 4223 de abril de 2010 em seu Art. 1ํㅜ parágrafos:

IV - Geradores de Resíduos de Construção: pessoas físicas ou jurídicas, públicas ou privadas, proprietárias ou responsáveis por obra de construção civil ou empreendimento com movimentação de terra, e que produzem resíduos de construção civil.

VI - Transportadores de Resíduos de Construção: pessoas físicas ou jurídicas, encarregadas da coleta e do transporte dos resíduos entre as fontes geradoras e as áreas de destinação.

X - Áreas de Transbordo e Triagem de resíduos de construção (ATT): são os estabelecimentos privados que se destinam ao recebimento de resíduos da construção civil e resíduos volumosos gerados e coletados por agentes privados, cujas áreas sem causar danos á saúde pública e ao meio ambiente deverão ser usadas para triagem dos resíduos recebidos, eventual transformações e posterior remoção para adequada disposição.

Entende-se que os geradores, transportadores e o poder público e municipal são responsáveis pelo controle, geração e destinação dos RCD. A Lei no 3.754, de 15 de julho de 2007 "institui a política municipal de proteção, preservação, conservação, controle e recuperação do meio ambiente e de melhoria da qualidade de vida no Município de Montes Claros, suas bases normativas, fins e mecanismos de regulação" (PMMC, p. 01, 2007).

As Normas Técnicas Brasileiras (NBR), associadas às políticas públicas, representam importante ferramenta para possibilitar o entendimento e esclarecer a responsabilidade dos agentes públicos e dos geradores de resíduos estabelecendo diretrizes e responsabilidades na geração e destinação final de RCD. As NBR 15112, 15113, 15114, 15116 foram elaboradas pelos Comitês Técnicos e publicadas pela ABNT em 2004 a fim de tornar viável o manejo correto dos resíduos em áreas específicas.

As maiores preocupações referentes a geração descontrolada de resíduos de construção civil é o impacto ambiental causado pela deposição irregular desses resíduos em terrenos baldios, margens de córregos e vias públicas.

Os impactos ambientais implicam em prejuízos não só a paisagem e a qualidade de vida da população são situações de custos sociais interligados, pessoais e públicos em função do comprometimento da capacidade de drenagem nos espaços urbanos e dos resultados em épocas de cheia, comprometimento da capacidade viária, possibilita da multiplicação de vetores epidêmicos e obrigatoriedade da atuação pública corretiva para minimizar as deposições irregulares de entulhos.

Para sancionar esses infratores que causam danos ao meio ambiente e a qualidade de vida da população através das deposições irregulares de RCD, o poder público deveria utilizar as Leis Vigentes.

A lei federal de crimes ambientais $\mathrm{n}^{\mathrm{o}} 12.305$ de 2 de agosto de 2010 em seu Art. 54 diz que, "se o crime ocorrer por lançamento de resíduos sólidos, líquidos ou gasosos, ou detritos, óleos ou substancias oleosas, em desacordo com as exigências estabelecidas em leis ou regulamentos" o infrator terá como pena "a reclusão de um a cinco anos". (BRASIL, 2010). Esta Lei exige ainda uma gestão integrada de resíduos sólidos ou um plano de gerenciamento em conformidade com as Resoluções CONAMA no 307/02 e no $408 / 10$.

A Resolução CONAMA nº 307/02, exige do poder público municipal a elaboração de leis, decretos, portarias e outros instrumentos legais, como parte da construção da política pública que faça obedecer além de impor responsabilidades aos agentes envolvidos no que se refere correta 
destinação dos RCD, e a Resolução CONAMA $408 / 10$ altera os artigos $2^{\circ}, 4^{\circ}, 5^{\circ}, 6^{\circ}, 8^{\circ}, 10^{\circ}$ e $11^{\circ}$ da Resolução 307/02.

\section{Conclusões}

A disposição dos resíduos sólidos oriundos da construção civil é um dos principais problemas urbanos encontrados na cidade de Montes Claros (MG). A pesquisa possibilitou a compreensão dos agentes envolvidos na geração, tratamento e disposição de resíduos sólidos da construção e demolição na cidade, onde ficou constatado que os mesmos são depositados em diferentes pontos da cidade de forma irregular, o que provoca degradação ao meio ambiente, impactos sociais e riscos à qualidade de vida da população. Este fato pode estar relacionado a diversos fatores, como a falta de consciência da população, o descaso por parte dos órgãos responsáveis pela fiscalização, falta de locais apropriados e estruturas adequadas para a deposição dos resíduos.

Entretanto o que pode ser observado pelos resultados deste estudo é que apesar de existir mecanismos para se formar uma base administrativa que assegure o cumprimento das normas no órgão gestor municipal, os instrumentos legais de fiscalização também são necessários e não são suficientes para que seus objetivos sejam implementados. Pode-se ampliar os mecanismos de gestão, complementando os instrumentos legais, com programas de informação e com a adição de programas de incentivos e conscientização dos agentes envolvidos para que a problemática dos RCD seja minimizada no município.

A necessidade da implementação das leis vigentes e responsabilidades do poder público e sociedade quanto à geração e destinação final dos resíduos sólidos da construção civil necessita de mudanças, que introduzidas nos processos construtivos, com o objetivo de minimizar os custos e a quantidade de resíduos gerados, contribuirá para a amenização desta problemática, visto que sempre haverá uma quantia produzida de maneira inevitável, que somado aos resíduos de demolição, ainda representará um volume significativo. Dessa forma, o estudo de soluções e práticas que apontem para a reutilização do entulho na própria construção civil, contribui para diminuir o problema urbano dos depósitos clandestinos deste material - proporcionando melhorias do ponto de vista ambiental - e introduz no mercado um novo material com grande potencialidade de uso e sustentável.

Conclui-se, com estes dados levantados, que o processo de implantação de programas de gerenciamento de resíduos da construção e demolição, certamente contribuirá para a redução do volume de resíduos gerados no município. No entanto, a quantidade de entulho produzido não diminuirá repentinamente.

\section{Referências}

ABNT, ASSOCIAÇÃO BRASILEIRA DE NORMAS TÉCNICAS. NBR 15112: Resíduos da construção civil e resíduos volumosos Áreas de transbordo e triagem - Diretrizes para projeto, implantação e operação. Rio de Janeiro/RJ, 2004.

ABNT, ASSOCIAÇÃO BRASILEIRA DE NORMAS TÉCNICAS. NBR 15113: Resíduos sólidos da construção civil e resíduos inertes Aterros - Diretrizes para projeto, implantação e operação. Rio de Janeiro/RJ, 2004.

ABNT, ASSOCIAÇÃO BRASILEIRA DE NORMAS TÉCNICAS. NBR 15114: Resíduos sólidos da construção civil - Áreas de reciclagem - Diretrizes para projeto, implantação e operação. Rio de Janeiro/RJ, 2004.

ABNT, ASSOCIAÇÃO BRASILEIRA DE NORMAS TÉCNICAS. NBR 15115: Agregados reciclados de resíduos sólidos da construção civil - Execução de camadas de pavimentação - Procedimentos. Rio de Janeiro/RJ, 2004.

ABNT, ASSOCIAÇÃO BRASILEIRA DE NORMAS TÉCNICAS. NBR 15116: Agregados reciclados de resíduos sólidos da construção civil - Utilização em pavimentação e preparo de concreto sem função estrutural Requisitos. Rio de Janeiro/RJ, 2004.

BRASIL, MINISTÉRIO DO MEIO AMBIENTE, CONSELHO NACIONAL DO MEIO AMBIENTE - CONAMA. Resolução nº 307, 
de 05 de julho de 2002. Estabelece diretrizes, critérios e procedimentos para a gestão dos resíduos da construção civil. Diário Oficial da República Federativa do Brasil, Brasília, DF, no 136, 17 de julho de 2002. Seção 1, p. 95-96.

BRASIL, MINISTÉRIO DO MEIO AMBIENTE, CONSELHO NACIONAL DO MEIO AMBIENTE - CONAMA. Resolução no 408, de 18 de janeiro de 2010. Altera os artigos $2^{\circ}$, $4^{\circ}, 5^{\circ}, 6^{\circ}, 8^{\circ}$, 9우 $10^{\circ}$ e $11^{\circ}$ da Resolução 307/02. Diário Oficial da República Federativa do Brasil, Brasília, DF, no 14,19 de janeiro de 2010.

BRASIL, MINISTÉRIO DO MEIO AMBIENTE, PRESIDENCIA DA REPÚBLICA. Casa Civil: Lei de crimes ambientais no 12.305 , de 02 de agosto de 2010. Institui a Política Nacional de Resíduos Sólidos; altera a Lei no 9.605, de 12 de fevereiro de 1998; e dá outras providências. Diário Oficial da República Federativa do Brasil, Brasília, DF, noำ 122, 02 de agosto de 2010. Seção 1, p. 63.

FOGLIATTI, M. C.; FILIPPO,S.; GOURDARD, B. Avaliação de impactos ambientais: aplicação aos sistemas de transportes. Rio de Janeiro: Interciência, 2004. 249 p.

GOOGLE MAPS. Mapa da cidade de Montes Claros (MG). Disponível em: < https://maps.google.com/maps?ll=-16.615634,$43.9384 \& \mathrm{z}=7 \& \mathrm{t}=\mathrm{m} \& \mathrm{hl}=\mathrm{en}-$

US\&gl=US\&mapclient=apiv3> acesso em 03 jun. de 2013.

IBGE, (2013). Instituto Brasileiro de Geografia e Estatística: Diretório de Pesquisas. Disponível em: < http://cod.ibge.gov.br/23253> Acesso: 19 fev. 2014.

IGA - Instituto de Geociências Aplicadas. Cidades. Disponível em: $<$ http://licht.io.inf.br/mg_mapas/mapa/cgi /iga_comeco1024.htm $>$, Acessado em 08 de abril de 2015.

KARPINSKI, A.K.; PANDOLFO. A.; REINEHR, R.; GUIMARÃES, J.; KUREK, J.; PANDOLFO, L.; ROJAS, J.W.J. Gestão de Resíduos da construção civil: uma abordagem prática no município de Passo Fundo. Disponível em: < http://www.estudostecnologicos.unisinos.br/ pdfs/86.pdf> acesso em 18 maio 2012.

MARCONI, Marina de Andrade; LAKATOS, Eva Maria. Técnicas de Pesquisas. 4. ed. São Paulo: Atlas, 1999.

MARQUES NETO, J. C. Gestão dos resíduos de construção e demolição no Brasil. São Carlos - SP: RIMA, p. 162. 2005.

PMMC, PREFEITURA MUNICIPAL DE MONTES CLAROS. Lei № 4.223, de 27 de abril de 2010: Institui o sistema de gestão sustentável de resíduos da construção civil e resíduos volumosos e dá outras providencias. Disponível em $<$ http://www.montesclaros.mg.gov.br/semma /index.htm> Acesso: 17 fev. 2013.

PMMC, PREFEITURA MUNICIPAL DE MONTES CLAROS. Procuradoria Jurídica. Lei № 3.754, de 15 de junho de 2.007: Dispõe sobre a política municipal de proteção, preservação, conservação, controle e recuperação do meio ambiente e de melhoria da qualidade de vida do município de Montes Claros, seus fins, mecanismos de regulação, e dá outras providencias. Disponível em $<$ http://www.montesclaros.mg.gov.br/semma /index.htm> Acesso: 17 nov. 2012.

SOUZA, U.E.L. de.; PALIARI, J.C.; AGOPYAN, V.; ANDRADE, A. C. de. Diagnóstico e combate à geração de resíduos na produção de obras de construção de edifícios: uma abordagem progressiva. Ambiente Construído, v. 4, ed. 4, Porto Alegre, 2004.

TEIXEIRA, Claudia Alkmim Guimarães. Estudo das destinações finais dos resíduos sólidos da construção civil no contexto urbano de Montes Claros. Disponível em: < http://www.ccsa.unimontes.br/ppgds/im ages/dissertacoes/2008/claudia_alkmim_g uimaraes_teixeira.pdf $>$ acesso em 18 maio de 2010. 